\title{
Immunolocalization of fibronectin and laminin within rat blastocysts cultured under serum-free conditions
}

\author{
J. A. Carnegie \\ Human IVF Laboratories, Reproductive Biology Unit, Department of Obstetrics and Gynecology, \\ The Loeb Institute for Medical Research, Ottawa Civic Hospital, Ottawa, Ontario, \\ Canada K1Y $4 E 9$
}

\begin{abstract}
Summary. Blastocysts ( $\sim 50$ per female) were collected on Day 5 of gestation from immature Sprague-Dawley rats superovulated using FSH/hCG-loaded mini-osmotic pumps and a single injection of the LHRH analogue, des-gly ${ }^{10}$ (D-ala ${ }^{6}$ )-LHRHethylamide. The cytoplasmic distribution of fibronectin and laminin was determined by immunofluorescence within these blastocysts, either immediately following their isolation or after they had been cultured in serum-free medium for $48-96 \mathrm{~h}$ (to allow trophectodermal cell attachment and outgrowth). In addition, inner cell masses (ICMs; isolated by immunosurgery) were cultured under serum-free conditions and immunofluorescently stained for the presence of the two adhesive glycoproteins. Within the freshly isolated blastocysts, positive immunostaining was obtained only for fibronectin and this was associated with the trophectodermal layer. After $48-96 \mathrm{~h}$ of culture, the cytoplasm of all trophectodermal cells contained both fibronectin (organized as a slightly granular network) and laminin (the staining pattern was distinctly punctate and perinuclear concentrations of immunoreactivity were evident). ICM-cells stained intensely for the presence of laminin at 48,72 and $96 \mathrm{~h}$ of culture, but appeared to contain little to no fibronectin. While further studies using serum-free culture are needed to define the hormonal regulation of this process, these findings support a role for early gestation rat trophectodermal cells, in addition to the established involvement of ICM-derived parietal endodermal cells, in the synthesis of extracellular matrix components found in Reichert's membrane. The appearance of trophectoderm-associated fibronectin in freshly isolated blastocysts before the establishment of the parietal endoderm layer may implicate this glycoprotein in the provision of a substrate for the migration of these cells as they form an endodermal lining to the blastocoele.
\end{abstract}

Keywords: fibronectin; laminin; blastocyst; trophectoderm; inner cell mass; extracellular matrix

\section{Introduction}

The early steps of embryonic development are characterized by a tremendous amount of cellular movement and reorganization as the basic cell lineages emerge which will give rise to the placenta and the embryo itself. A key initial step following formation of the blastocyst is the differentiation and migration of parietal endodermal cells from the inner cell mass (ICM)-derived primitive endoderm to form an inner lining to the trophectoderm, thereby contributing an important component to the parietal yolk sac placenta (Enders et al., 1978). Reichert's membrane, a specialized basement membrane containing type IV collagen, fibronectin, laminin, entactin, and heparan sulphate proteoglycan (Timpl et al., 1979; Hogan et al., 1980; Smith \& Strickland, 1981; Semoff et al., 1982), also begins to be deposited on the inner aspect of the trophectoderm at this stage of development (Enders et al., 1978). It may be that this basement membrane, in addition to having a selective 
filtrative role as a key component of the yolk sac placenta (Clark et al., 1975), also facilitates the migration of the parietal endodermal cells along the inner surfaces of the trophectoderm.

During embryonic development, migrating cells frequently move over extracellular material which is supplied, not by the translocating cells themselves, but rather by the cells over which this movement is taking place (Fujimoto et al., 1985; Alvarez-Buylla \& Merchant-Larios, 1986; Richoux et al., 1989). However, the results of ultrastructural and metabolic labelling studies using mid-gestation rat and mouse tissues have strongly supported a role for the parietal endodermal cells, and not the trophoblastic cells, in the production of these proteins (Jollie, 1968; Clark et al., 1975; Minor et al., 1976a, b; Amenta et al., 1983). But this stage of pregnancy immediately precedes the degeneration of the trophoblastic layer and the establishment of the chorioallantoic placenta (Minor et al., 1976b; Semoff et al., 1982) and may not represent the optimal time at which to assess trophoblastic cell function. It is proposed that, during the initial stages of the deposition of Reichert's membrane, both the trophectodermal and the parietal endodermal cells participate in the synthesis of the various components. Furthermore, specific components capable of influencing cell movement, such as fibronectin, may be deposited early in blastocyst differentiation by the trophectodermal cells to facilitate parietal endoderm migration. As an initial step toward examining this hypothesis, immunofluorescence was used to determine whether trophectodermal and ICM-cells [from freshly isolated preimplantation rat blastocysts and those which had been cultured (48-96 h)] contain fibronectin and laminin, two key components of Reichert's membrane with well-recognized roles in cellular adhesion and migration.

\title{
Materials and Methods
}

\begin{abstract}
Animal superovulation and collection of blastocysts. The development of numerous ovarian follicles was stimulated in immature female Sprague-Dawley rats $(65-70 \mathrm{~g}$ body weight) using Alzet mini-osmotic pumps (Alzet model 2001; Alza Corp., Palo Alto, CA, USA) containing a gonadotrophin mixture previously shown to be optimal for superovulation induction (Armstrong \& Opavsky, 1988; Leveille \& Armstrong, 1989). Each pump (200 $\mu$ l loading volume; $1 \mu \mathrm{l} /$ h pumping rate) contained sufficient quantities of a highly purified ( $\mathrm{LH} / \mathrm{FSH}$ activity $=0.024 \%$ ) preparation of pig follicle-stimulating hormone (FSH; Batch Number V001; Vetrepharm Inc., London, Ontario, Canada) and human chorionic gonadotrophin (hCG; Provet Chorionic Gonadotropin, Ayerst Labs, Montreal, Quebec, Canada) in sterile saline to deliver $120 \mu \mathrm{g} / 24 \mathrm{~h}$ (equivalent to $1 \mathrm{mg} \mathrm{NIH}-\mathrm{FSH}-\mathrm{SI} / 24 \mathrm{~h}$ ) and $0.2 \mathrm{i} . \mathrm{u} . / 24 \mathrm{~h}$, respectively, of the two gonadotrophic hormones. The pumps were inserted subcutaneously into halothane-anaesthetized animals on the morning $(09: 00-10: 00 \mathrm{~h})$ of Day -2 . Ovulation times were synchronized by an injection ( $100 \mathrm{ng}$; i.p.) $52 \mathrm{~h}$ later of a luteinizing hormone-releasing hormone analogue $\left[\mathrm{des}_{-g l y}{ }^{10}\left(\mathrm{D}-\mathrm{ala}^{6}\right)\right.$-LHRH-ethylamide; Sigma Chemical Co., St Louis, MO, USA] and the animals were mated overnight. The pumps were removed the following morning (09:00-10:00 h of Day 1), rinsed in sterile saline and immediately inserted into a second group of animals (duration of pumping $=8$ days) to be used for the induction of follicular development in these animals as well. All rats were killed on the afternoon of Day 5 of pregnancy and the uterine horns were removed and flushed with Opti-MEM 1 Reduced Serum Medium (Opti-MEM 1; GIBCO Laboratories, Mississauga, Ontario, Canada) to obtain a mixture of both zona-enclosed and zona-free blastocysts. Opti-MEM 1, a Hepes-buffered modification of Eagle's Minimal Essential Medium containing $\mathrm{NaHCO}_{3}(2.4 \mathrm{~g} / \mathrm{l})$, non-essential amino acids $(0.1 \mathrm{~mm})$, penicillin-streptomycin $(50000 \mathrm{U}$ and $50000 \mu \mathrm{g} / \mathrm{l}$, respectively) and 2-mercaptoethanol $\left(5.5 \times 10^{-5} \mathrm{M}\right.$ ) (all from GIBCO) was used as a basic medium for all the culture-related procedures and supplemented as indicated below to produce the different treatment groups.
\end{abstract}

Culture of blastocysts. Blastocysts were cultured $\left(37^{\circ} \mathrm{C} ; 5 \% \mathrm{CO}_{2}\right.$ in air) in 8-chamber Lab-Tek chamber slides (GIBCO) containing $300 \mu \mathrm{l}$ Opti-MEM 1 supplemented with $0 \cdot 25 \%$ bovine serum albumin (BSA, Fraction V), $2 \%$ controlled process serum replacement-2 (CPSR-2) and 0.05\% fetuin (all from Sigma; mod-Opti-MEM 1), and in the presence or absence of human plasma fibronectin $(5 \mu \mathrm{g} / \mathrm{ml}$; Collaborative Research Inc., Bedford, MA, USA) or basement membrane-derived laminin $(10 \mu \mathrm{g} / \mathrm{ml}$; Collaborative Research). Culture was for $48-96 \mathrm{~h}$ with medium collection and replacement (when appropriate) after the first $48 \mathrm{~h}$. In those experiments in which blastocyst outgrowth was to be compared in the presence or absence of serum, a proportion of the blastocysts were cultured in Opti-MEM 1 supplemented $(10 \%)$ only with heat-inactivated fetal bovine serum (GIBCO).

Isolation and culture of inner cell masses. Inner cell masses (ICMs) were isolated from blastocysts by immunosurgery (Solter \& Knowles, 1975). Antibodies to rat spleen cells were induced in 2 New Zealand White rabbits by the administration of 3 fortnightly injections of $3 \mathrm{ml}$ Dulbecco's phosphate-buffered saline (D-PBS; calcium- and magnesium-free; GIBCO) containing $1.3 \times 10^{8}$ rat spleen cells $/ \mathrm{ml}$. At 10 days after the final spleen cell injection, the rabbits were bled and the resultant serum was heat-inactivated $\left(30 \mathrm{~min}\right.$ at $\left.56^{\circ} \mathrm{C}\right)$ and then stored in aliquants at $-80^{\circ} \mathrm{C}$ until required for ICM isolation. Blastocysts were precultured $(18 \mathrm{~h})$ in mod-Opti-MEM 1 to allow those blastocysts 
still zona-enclosed at the time of isolation to undergo hatching. The blastocysts were then taken through microdrops of the following solutions to selectively lyse the trophectodermal cells: rabbit antiserum to rat spleen cells (diluted 1 in 20 with BSA-supplemented Opti-MEM 1; $30 \mathrm{~min}$ at $37^{\circ} \mathrm{C}$ ); 3 wash drops of BSA-Opti-MEM 1; guinea-pig complement (diluted 1 in 16 with BSA-Opti-MEM 1; 30 min at $37^{\circ} \mathrm{C}$; GIBCO). The blastocysts (most of the lysed trophectodermal cells were still attached) were transferred to $1 \mathrm{ml}$ BSA-Opti-MEM 1 and a fine bore $(40-50 \mu \mathrm{m})$ micropipette was used to free the intact ICMs from the trophectodermal cellular debris. Finally, these ICMs were cultured (96 h) as described for the blastocysts, but on surfaces which had been precoated with collagen IV $\left(5 \mu \mathrm{g} / \mathrm{cm}^{2}\right.$; Collaborative Research) to facilitate the attachment of the ICM-derived cells.

Immunolocalization of fibronectin or laminin. Fibronectin or laminin was localized by immunofluorescence within freshly isolated blastocysts (blastocysts were transferred from one solution to another) or within blastocysts or ICMs attached to Lab Tek chamber slides after $48-96 \mathrm{~h}$ of culture. In both cases, the blastocysts (ICMs) were fixed ( 5 min at room temperature) with 3.7\% paraformaldehyde in phosphate-buffered saline (PBS, $\mathrm{pH} 7.0$ ) and then permeabilized (20 min at room temperature) with 0.1\% (in PBS) Nonidet P-40 (Sigma) to render intracellular fibronectin (or laminin) accessible to the primary and secondary antibodies (Turksen et al., 1984; Carnegie, 1990). The blastocysts (ICMs) were rinsed with PBS and then incubated ( $45 \mathrm{~min}$ at room temperature per antibody) with either a specific antiserum to human fibronectin raised in the goat (Terochem Laboratories Ltd, Toronto, Ontario, Canada) followed by fluorescein isothiocyanate (FITC)- or rhodamine-labelled pig anti-goat IgG (Intermedico, Willowdale, Ontario, Canada) or with a specific, rabbit-derived antiserum to mouse laminin (Collaborative Research) followed by FITC-labelled goat anti-rabbit IgG (Intermedico). The slides were then mounted in $0.1 \%$-phenylenediamine in $50 \%$ glycerol (to retard bleaching of fluorescence during ultraviolet illumination; Johnson \& Nogueira-Araujo, 1981) and observed with a Carl Zeiss microscope equipped with epifluorescence optics. Either fibronectin or laminin was immunolocalized in 4-8 blastocysts at each of the 4 time periods $(0,48,72$ or $96 \mathrm{~h}$ of culture) and each time period was repeated in 2-4 experiments. These glycoproteins were immunolocalized in ICM-cells at only the $96 \mathrm{~h}$ time interval. Each experiment was accompanied by control blastocysts (3-4 per time period for each fibronectin and laminin localization) for which incubation with the appropriate first antibody was omitted.

Quantification of blastocyst outgrowth by morphometric analysis. Blastocysts cultured ( $72 \mathrm{~h}$ ) under various serumfree conditions or in the presence of serum were photographed onto $35 \mathrm{~mm}$ Plus X film using a Leitz inverted microscope. Using a Videoplan image analysis system in combination with a Tamron Fotovix film video processor, each blastocyst-derived cell complex was traced with a cursor and the area which it occupied on the culture surface calculated. All data were treated statistically by analysis of variance and the significance of difference between treatment groups was determined by Duncan's multiple range test.

\section{Results}

\section{Blastocyst culture}

For this investigation, 2897 blastocysts were collected from 57 superovulated rats on Day 5 of pregnancy. The mean blastocyst yield was $50 \cdot 8 \pm 2 \cdot 3$ per female and was not influenced by allocation to either the first $(51.9 \pm 2.9$ blastocysts/rat) or second $(49.7 \pm 3.6)$ group of animals to be implanted with each batch of FSH/hCG-loaded mini-osmotic pumps. At $24 \mathrm{~h}$ of culture, all blastocysts were still free-floating; however, those that were zona-enclosed at the time of isolation had now completed the hatching process (Fig. 1a). Over the ensuing 24-h period, the blastocysts collapsed and began to attach to and to spread on the culture surface (Fig. 1b). Cellular attachment and outgrowth appeared to be equivalent whether the embryos were maintained in the presence of fibronectin or of laminin; under both culture conditions, trophectodermal cells viewed at $72 \mathrm{~h}$ and $96 \mathrm{~h}$ of culture became progessively more flattened and well-separated from one another (Figs 1c, 1d). Inner cell mass-derived cells (smaller and more rounded in shape than the trophectodermal cells) usually remained on top of the trophectoderm and migrated to varied extents, such that they formed either a centrally-located cell cluster (Fig. 1c, arrowheads) or several smaller islets of cells (Fig. 1d, arrowheads) attached to the upper surfaces of the trophectodermal cells.

Table 1 summarizes the outgrowth of blastocysts cultured for $72 \mathrm{~h}$ in serum-supplemented $(10 \%)$ Opti-MEM 1 or under the three serum-free culture conditions used for this study. While the presence of fetal bovine serum is associated with a considerably greater extent of trophectodermal cell proliferation and outgrowth (6-7-fold; $P<0 \cdot 01)$, trophectodermal cell attachment and spreading (2.3-2.7-fold; $P<0.01)$ was still supported by mod-Opti-MEM 1 (Table 1; Fig. 1), thereby allowing the distribution of laminin and fibronectin within the flattened trophectodermal cells to be 

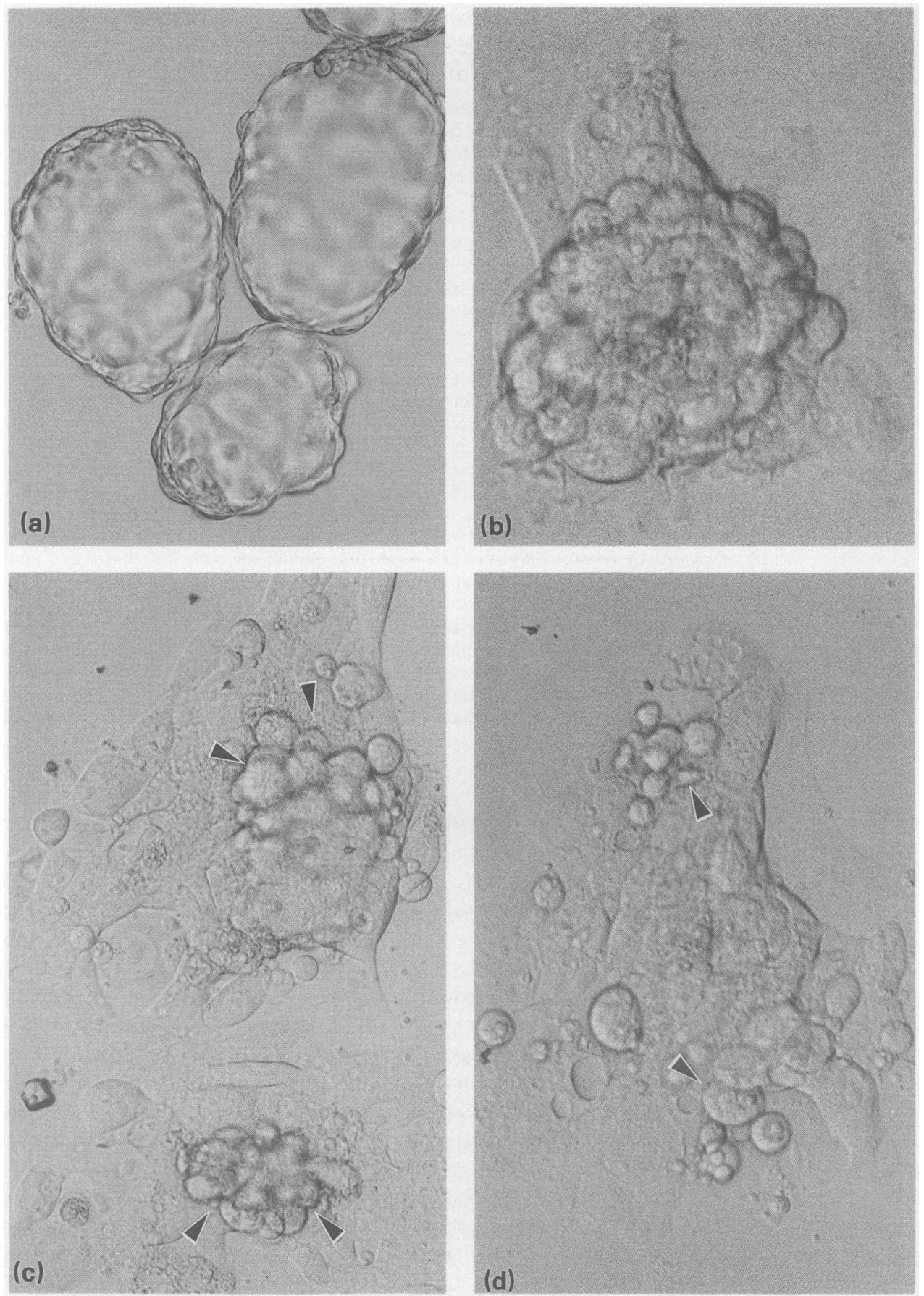

Fig. 1. Rat blastocysts after 24 (a), 48 (b) and $72 \mathrm{~h}$ (c, d) of culture in mod-Opti-MEM 1 supplemented with laminin. A cluster of ICM-cells (arrowheads) can be seen lying on top of flattened, spread trophectodermal cells in each of the two blastocysts shown in (c), while the ICM-cells in (d) have dispersed into several small clusters. $\times 380$. 
readily visualized. While the extent of outgrowth was similar among the three serum-free treatment groups $(P>0.05)$, trophectodermal cell attachment appeared to be more tenuous when blastocysts were cultured in mod-Opti-MEM 1 alone (no fibronectin or laminin) in that these blastocysts were occasionally dislodged during the fixation, permeabilization and washing steps associated with immunolocalization.

Table 1. Mean areas occupied by rat blastocysts* after culture for $72 \mathrm{~h}$ in mod-Opti-MEM $1 \pm$ fibronectin or laminin or in Opti-MEM 1 supplemented with fetal bovine serum

\begin{tabular}{lc}
\hline Culture medium & $\begin{array}{c}\text { Area occupied on culture } \\
\text { surface }\left(\mathrm{mm}^{2} \times 10^{-3}\right)\end{array}$ \\
\hline $\begin{array}{l}\text { Mod-Opti-MEM 1 } \\
\text { Mod-Opti-MEM } 1+ \\
\text { fibronectin }(5 \mu \mathrm{g} / \mathrm{ml})\end{array}$ & $26 \pm 2$ \\
$\begin{array}{l}\text { Mod-Opti-MEM 1+ } \\
\text { laminin }(10 \mu \mathrm{g} / \mathrm{ml})\end{array}$ & $30 \pm 2$ \\
$\begin{array}{l}\text { Mod-Opti-MEM } 1+ \\
\text { fetal bovine serum }(10 \%)\end{array}$ & $31 \pm 5$ \\
\hline
\end{tabular}

Values are mean \pm s.e.m. $(n=15,3$ exps).

*Initial area occupied on culture surface by expanded, hatched blastocysts before trophectodermal cell attachment is $11.5 \pm 0.6 \times 10^{-3} \mathrm{~mm}^{2}(n=15)$.

\section{Fibronectin immunolocalization}

Positive immunostaining for fibronectin was observed in freshly isolated, detergentpermeabilized blastocysts, both within the cellular cytoplasm and as a fine outline to individual trophectodermal cells (Fig. 2a). A non-specific yellow-orange nuclear autofluorescence was frequently observed in some trophectodermal cells following paraformaldehyde fixation and permeabilization with detergent. This allowed the two trophectodermal cells in mitosis in the blastocyst shown in Fig. 2a (small arrowheads) to be easily recognized. Following the collapse of the blastocysts, the presence of fibronectin was readily seen within the cytoplasm of the spreading trophectodermal cells at 48,72 and $96 \mathrm{~h}$ of culture (Figs $2 \mathrm{~b}-\mathrm{f}$ ). At higher magnification, this fibronectin appeared as a network of somewhat granular material (Figs $2 \mathrm{~d} \& \mathrm{f}$ ). In some instances, a fibrillar pattern of fibronectin immunolocalization was seen, either where the cells had been more extensively digested by the detergent (Fig. 2d, arrowheads; phase contrast showed much loss of plasma membrane and cytoplasmic contents) or in spaces adjacent to the trophectodermal cells (Figs 2e \& f, arrowheads).

Inner cell mass-derived cells (ICM-cells), distinguished from trophectodermal cells by their smaller size and either rounded or spindle shape, remained on top of the centrally-located trophectodermal cells within the blastocysts shown in Figs 2(b) and 2(c). While they did not stain more positively for fibronectin than the surrounding trophectodermal cells, their presence on top of fibronectin-positive trophectoderm made it difficult to state with certainty whether these cells also contain the adhesive glycoprotein. Repeated efforts to immunolocalize fibronectin within cells derived from the culture ( 72 or $96 \mathrm{~h}$ ) of ICMs isolated by immunosurgery consistently revealed an extremely low level of cytoplasmic fluorescence within these cells (Fig. 4b). While the level of this fluorescence was slightly higher than that observed in the control ICM-cells (incubated with FITC pig anti-goat IgG only; devoid of cytoplasmic fluorescence), the staining was diffuse, 

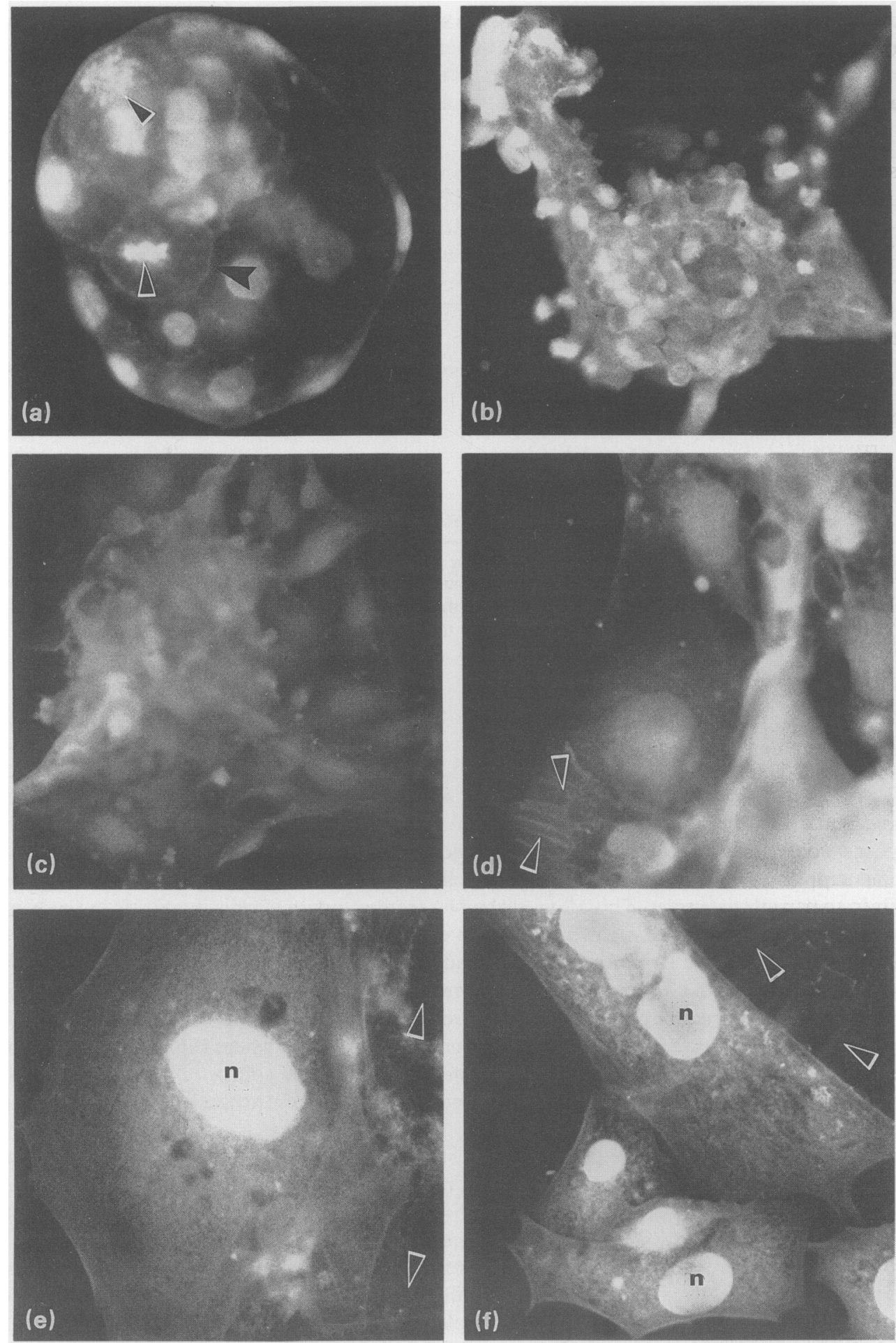
without subcellular pattern and sufficiently weak to be considered non-specific background fluorescence.

\section{Laminin immunolocalization}

In contrast to fibronectin, little to no positive immunostaining for laminin was observed in the freshly isolated, detergent-permeabilized blastocysts (Fig. 3a). However, both trophectodermal and, to a greater extent, ICM-cells displayed strong cytoplasmic laminin immunoreactivity after 48-96 h of culture (Figs 3b-d). The centrally located ICM-cells were readily distinguished in these embryos by their high level of cytoplasmic fluorescence (Figs $3 \mathrm{~b}-\mathrm{d}$; arrowheads). A punctate pattern of laminin distribution was evident in the more spread and flattened trophectodermal cells (Figs 3e-f, arrowheads). A high level of staining was frequently observed in the perinuclear regions of these cells (Figs 3e \& $\mathrm{f}$ ).

As with the intact blastocysts, the cytoplasm of cultured ICM-cells contained a high quantity of immunoreactive laminin (Fig. 4a). In addition, streaks of laminin, presumably deposited by the ICM-cells, were seen in association with the collagen IV-coated surfaces between these cells (Fig. 4a, arrowheads).

\section{Discussion}

This paper describes the collection of about 50 blastocysts per female rat and their culture in serumfree medium. A high rate of embryonic development was observed when superovulation was induced using FSH/hCG-loaded mini-osmotic pumps rather than PMSG. This has been attributed to lower circulating concentrations of androgens and oestrogens during the cleavage, compaction and cavitation stages which are occurring in the absence of a gonadotrophin (PMSG) with an excessively long biological half-life (Leveille \& Armstrong, 1989).

The successful culture of mouse blastocysts in serum-free medium has been reported. One study used EM-2 medium, a somewhat complex formulation composed of 50\% NCTC-109 (GIBCO) and 50\% PCM (Preimplantation Culture Medium; Goldstein et al., 1975) as well as numerous supplements (Rizzino \& Sherman, 1979). Other media (Eagle's basal medium, CMRL medium 1066 or a combination of Ham's F12 plus Dulbecco's modified Eagle's medium, all enriched with various supplements), required precoating of the culture dishes with fibronectin, laminin or type IV collagen to permit trophectodermal cell attachment and outgrowth (Carson et al., 1988; Sutherland et al., 1988). In this study, a commercially available medium (Opti-MEM 1, a special formulation from GIBCO with reduced serum requirements), supplemented only with BSA, CPSR-2 and fetuin, supported the hatching, attachment and outgrowth of rat blastocysts. While the extent of blastocyst outgrowth was not equivalent to that observed with serum-supplemented Opti-MEM 1, trophectodermal cell attachment and spreading as well as giant cell transformation did occur, thereby allowing the presence of extracellular matrix proteins within these cells to be evaluated in the absence of undefined serum influences. It has been reported that the attachment-associated

Fig. 2. Immunolocalization of fibronectin within a freshly isolated blastocyst (a) or in blastocysts cultured for 48 (b), 72 (c, d) or $96 \mathrm{~h}$ (e,f) in mod-Opti-MEM 1 supplemented with laminin. All blastocysts were incubated with goat anti-human fibronectin and then with FITC-labelled pig anti-goat IgG after fixation in $3.7 \%$ paraformaldehyde followed by permeabilization with $0.1 \%$ Nonidet P-40. In the freshly isolated blastocyst (a), fibronectin delineates some of the trophectodermal cells (large arrowhead). Non-specific nuclear autofluorescence (yelloworange in colour) also reveals the condensed chromosomes (small arrowheads) of two trophectodermal cells in mitosis in this blastocyst. Fibrils of fibronectin are present adjacent to the trophectodermal cells (e, f; arrowheads) or where the cells have been more extensively digested by the detergent $(\mathrm{d}$, arrowhead). $\mathrm{n}=$ nucleus. $\times 690(\mathrm{a}, \mathrm{e}, \mathrm{f}) ; \times 275(\mathrm{~b}, \mathrm{c}, \mathrm{d})$. 

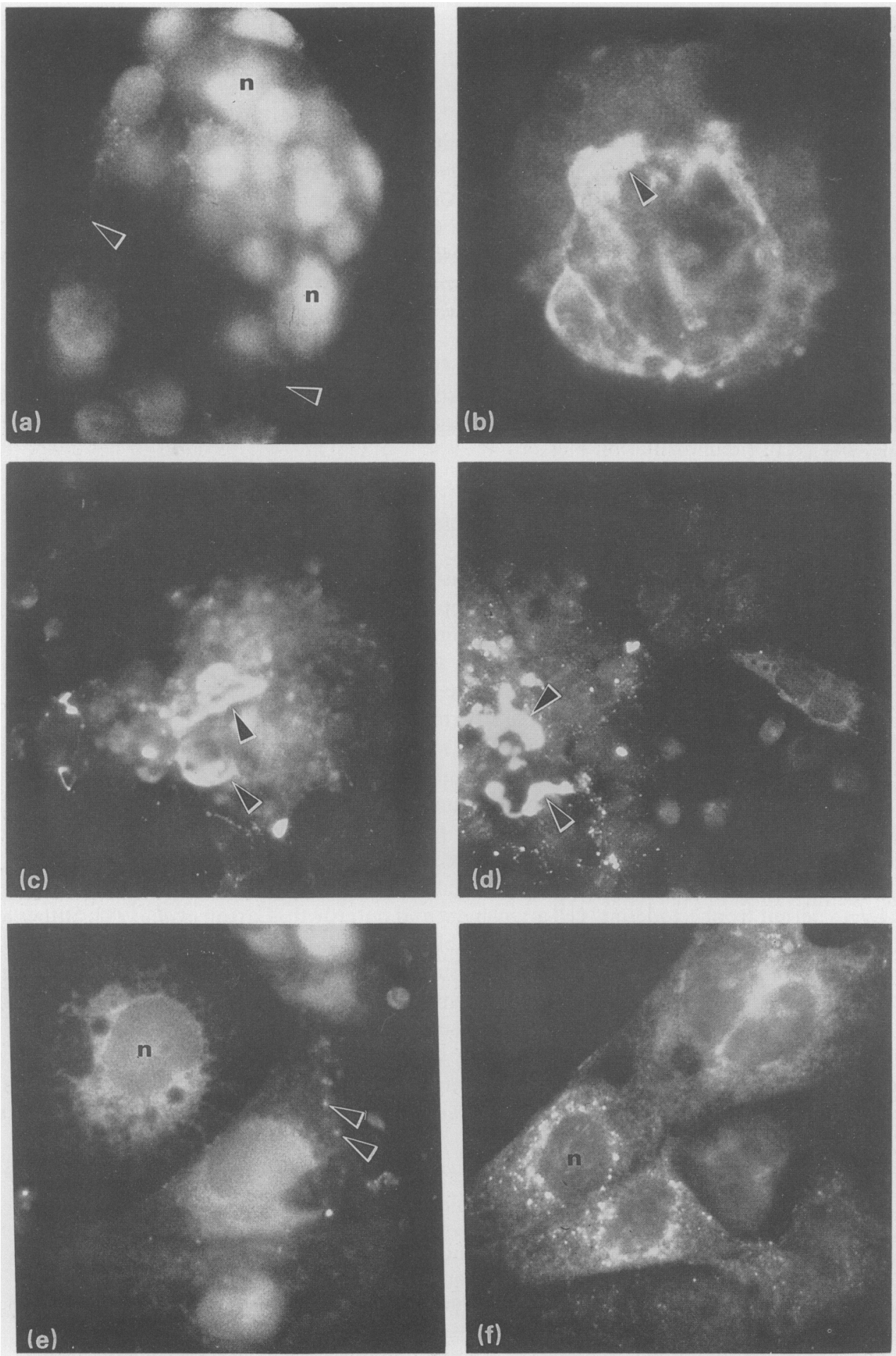
pattern of protein secretion by mouse blastocysts is the same, regardless of the presence of serum in the culture medium (Nieder, 1990). CPSR-2 is a bovine serum-derived serum substitute which contains undetectable levels of plasma-derived fibronectin $(<6 \mathrm{ng} / \mathrm{ml} ;$ J. A. Carnegie, unpublished observation) and has low mitogenic activity. Fetuin, a sialated glycoprotein serine protease inhibitor comprising $45 \%$ of fetal calf serum proteins (Fisher et al., 1958), promotes mouse trophectodermal cell attachment and outgrowth in vitro. Hence, a method for in-vitro maintenance of rat blastocysts in an environment free of serum-associated attachment factors is described. Trophectodermal cell attachment and spreading is supported, thereby allowing laminin and fibronectin distributions within whole cells to be visualized with a reasonable level of resolution. In addition, this system provides a means for the subsequent evaluation of the hormonal regulation of laminin and fibronectin production by these cells (Rizzino \& Sherman, 1979).

In this study, rat trophectodermal cells were found to contain both fibronectin and laminin. This is the first report of the localization of either of these glycoproteins in rat blastocysts. Previous studies on the embryonic distribution of these proteins have confined themselves primarily to the mouse and the pig. In the mouse, fibronectin has been found both on the inner aspect of the trophectoderm of preimplantation blastocysts as well as within the cytoplasm of the endoderm, mesoderm and trophectoderm of implanting egg cylinders (Zetter \& Martin, 1978; Wartiovaara et al., 1979; Yohkaichiya et al., 1988). Fibronectin is also present on the blastocoelic face of the trophectoderm and within the trophectodermal cells of early pig embryos (Richoux et al., 1989). In mice and pigs, as well as in rats (present study), fibronectin deposition on the blastocoelic surface of the trophectoderm was observed before the migration of the inner endodermal layer had occurred. Indeed, Richoux et al. (1989) suggested that endodermal cell migration is facilitated in pig embryos by trophectodermally derived fibronectin.

A role for the trophectoderm rather than the endoderm in the production of fibronectin during the initial stages of Reichert's membrane deposition is further strengthened by the results obtained by immunostaining ICM-derived cells. Little to no cytoplasmic reaction for fibronectin was seen in these cells. The presence of fibronectin within the parietal and visceral endoderm of mouse egg cylinder stage embryos has been reported (Wartiovaara et al., 1979; Yohkaichiya et al., 1988) and the possibility cannot be ignored that the ICM-cells in intact blastocysts may contain some fibronectin whose synthesis is trophectodermally regulated. However, mid-gestation mouse parietal endoderm appears to be incapable of fibronectin synthesis (Jetten et al., 1979; Hogan, 1980) and, during the migration of pig endodermal cells, fibronectin was found only within the trophectodermal cells and at the interface between parietal endoderm and trophectoderm (Richoux et al., 1989). It would therefore appear that rat trophectodermal cells are at least the primary, if not the only, source of the fibronectin found in Reichert's membrane at the time of parietal endodermal cell differentiation and migration. Indeed, fibronectin is concentrated toward the trophoblastic side and is virtually absent from the endodermal side of mid-gestation mouse Reichert's membrane (Semoff et al., 1982). The secretion of fibronectin $(100-200 \mathrm{pg} /$ blastocyst $/ 48 \mathrm{~h})$ by cultured rat blastocysts has been measured by ELISA (J. A. Carnegie, unpublished observation) and metabolic labelling

Fig. 3. Immunolocalization of laminin within a freshly isolated blastocyst (a) or in blastocysts cultured for 48 (b), 72 (c) or $96 \mathrm{~h}$ (d, e, f) in mod-Opti-MEM 1 plus fibronectin. All blastocysts were incubated with rabbit anti-mouse laminin and then with FITC-labelled goat anti-rabbit IgG after fixation and permeabilization as indicated for Fig. 2. The fluorescence seen in (a) is primarily tissue preparation-induced, non-specific nuclear autofluorescence (yellow-orange in colour); the arrowheads indicate laminin-negative trophectodermal cytoplasm. At low magnification, ICM-cells can readily be distinguished from trophectodermal cells by their intense cytoplasmic staining for laminin (b, c, d; arrowheads). The granular pattern of trophectodermal cell laminin immunoreactivity is revealed in (e) (arrowheads) and (f). $n=$ nucleus. $\times 690(\mathrm{a}, \mathrm{e}, \mathrm{f}) ; \times 275(\mathrm{~b}, \mathrm{c}, \mathrm{d})$. 

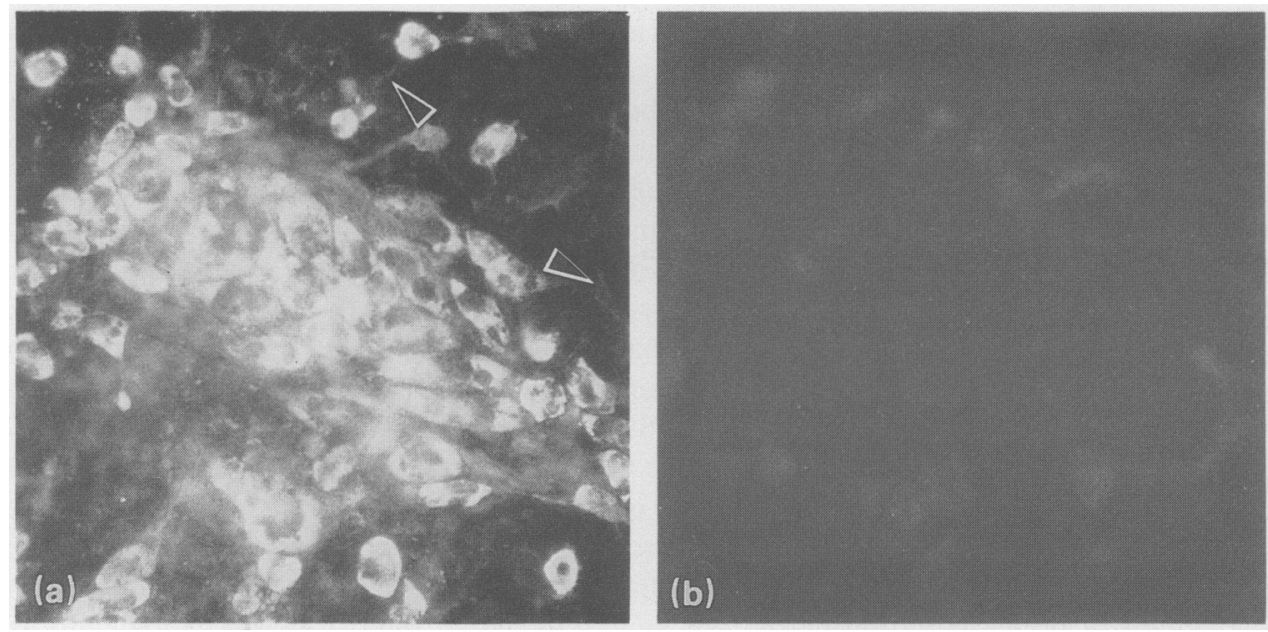

Fig. 4. Immunostaining for laminin (a) and fibronectin (b) within ICM-cells (isolated by immunosurgery) after $96 \mathrm{~h}$ of culture on collagen IV. Streaks of collagen-bound laminin (a; arrowheads) occur frequently in the vicinity of the ICM-derived cell clusters. $\times 275$.

has shown Day-6.5 mouse trophectoderm to be capable of fibronectin synthesis (Semoff et al., 1982).

Laminin is a marker for mouse parietal endoderm (Strickland, 1981) and its presence in the blastomeres of 8- and 16-cell mouse embryos has also been reported (Leivo et al., 1980; Wu et al., 1983). In this study, freshly isolated rat blastocysts did not stain strongly for the presence of this glycoprotein. However, once blastocyst collapse and trophectodermal cell attachment had occurred, all of the ICM-cells stained intensely with the laminin antibodies and a punctate pattern of laminin immunoreactivity was also discerned in the cytoplasm of each flattened and well-spread trophectodermal cell. Pig endodermal cells do not secrete laminin until the migration process has been completed; this laminin may therefore then stabilize the interactions between the stationary endodermal cells and the trophectoderm (Richoux et al., 1989).

In contrast to the rather uniform and granular pattern of cytoplasmic immunostaining for fibronectin, that for laminin was distinctly punctate and localized perinuclear concentrations of this glycoprotein were frequently observed. Similar intracytoplasmic laminin-containing vesicles have been described in pig endoderm (Richoux et al., 1989) and probably reflect the sequestering of this protein in the Golgi for glycosylation before secretion (Morita et al., 1985). The laminin immunostaining within the rat ICM-cells was too intense to permit the elucidation of its subcellular distribution.

This study has shown that laminin is the primary component of ICM cells whereas the trophectoderm cells of cultured preimplantation rat blastocysts contain fibronectin as well as laminin. These observations have been made using primarily cultured embryos and caution must be exercised when attempting to extend interpretations to embryos developing in vivo, but the hypothesis that both the trophectoderm and the parietal endoderm participate in the initial stages of Reichert's membrane synthesis is supported. Furthermore, the association of fibronectin with the trophectoderm in freshly isolated blastocysts, before both the appearance of laminin in this locale and the establishment of the parietal endoderm layer, may point to a role for this glycoprotein in facilitating endodermal cell migration.

I thank Vetrepharm Inc. (London, Ontario) for the highly purified preparation of FSH used in this investigation; and Mr Oliver Cabaca for excellent technical assistance. These studies were supported by a grant from the Medical Research Council of Canada (MA-10046). 


\section{References}

Alvarez-Buylla, A. \& Merchant-Larios, H. (1986) Mouse primordial germ cells use fibronectin as a substrate for migration. Expl Cell Res. 165, 362-368.

Amenta, P.S., Clark, C.C. \& Martinez-Hernandez, A. (1983) Deposition of fibronectin and laminin in the basement membrane of the rat parietal yolk sac: immunohistochemical and biosynthetic studies. $J$. Cell Biol. 96, 104-111.

Armstrong, D.T. \& Opavsky, M.A. (1988) Superovulation of immature rats by continuous infusion of follicle-stimulating hormone. Biol. Reprod. 39, 511-518.

Carnegie, J.A. (1990) The secretion of fibronectin by rat granulosa cells occurs primarily during early follicular development. J. Reprod. Fert. 89, 579-589.

Carson, D.D., Tang, J.P. \& Gay, S. (1988) Collagens support embryo attachment and outgrowth in vitro: effects of the Arg-Gly-Asp sequence. Devl Biol. 127, 368-375.

Clark, C.C., Minor, R.R., Koszalka, T.R., Brent, R.L. \& Kefalides, N.A. (1975) The embryonic rat parietal yolk sac. Changes in the morphology and composition of its basement membrane during development. Devl Biol. 46, 243-261.

Enders, A.C., Given, R.L. \& Schlafke, S. (1978) Differentiation and migration of endoderm in the rat and mouse at implantation. Anat. Rec. 190, 65-78.

Fisher, H.W., Puck, T.T. \& Sato, G. (1958) Molecular growth requirements of single mammalian cells: the action of fetuin in promoting cell attachment to glass. Proc. natn. Acad. Sci. USA 44, 4-10.

Fujimoto, T., Yoshinaga, K. \& Kona, I. (1985) Distribution of fibronectin on the migratory pathway of primordial germ cells in mice. Anat. Rec. 211, 271-278.

Goldstein, L.S., Spindle, A.I. \& Pederson, R.A. (1975) Xray sensitivity of the preimplantation mouse embryo in vitro. Radiation Res. 62, 276-287.

Hogan, B.L.M. (1980) High molecular weight extracellular proteins synthesized by endoderm cells derived from mouse teratocarcinoma cells and normal extraembryonic membranes. Devl Biol. 76, 275-285.

Hogan, B.L.M., Cooper, A.R. \& Kurkinen, M. (1980) Incorporation into Reichert's membrane of lamininlike extracellular proteins synthesized by parietal endoderm cells of the mouse embryo. Devl Biol. 80, 280-300.

Jetten, A.M., Jetten, M.E.R. \& Sherman, M.I. (1979) Analysis of cell surface and secreted proteins of primary cultures of mouse extraembryonic membranes. Devl Biol. 70, 89-104.

Johnson, D.C. \& Nogueira-Araujo, G.M. (1981) A simple method of reducing the fading of immunofluorescence during microscopy. J. Immunol. Meth. 43, 349-350.

Jollie, W.P. (1968) Changes in the fine structure of the parietal yolk sac of the rat placenta with increasing gestational age. Am. J. Anat. 122, 513-532.

Leivo, I., Vaheri, A., Timpl, R. \& Wartiovaara, J. (1980) Appearance and distribution of collagens and laminin in the early mouse embryo. Devl Biol. 76, $100-114$.
Leveille, M.C. \& Armstrong, D.T. (1989) Preimplantation embryo development and serum steroid levels in immature rats induced to ovulate or superovulate with PMSG injection or FSH infusions. Gamete Res. 23, 127-138.

Minor, R.R., Hoch, P.S., Koszalka, T.R., Brent, R.L. \& Kefalides, N.A. (1976a) Organ cultures of the embryonic rat parietal yolk sac. I. Morphologic and autoradiographic studies of the deposition of the collagen and noncollagen glycoprotein components of basement membrane. Devl Biol. 48, 344-364.

Minor, R.R., Strause, E.L., Koszalka, T.R., Brent, R.L. \& Kefalides, N.A. (1976b) Organ cultures of the embryonic rat parietal yolk sac. II. Synthesis, accumulation and turnover of collagen and noncollagen basement membrane glycoproteins. Devl Biol. 48, 365-376.

Morita, A., Sagimoto, E. \& Kitagawa, Y. (1985) Post translational assembly and glycosylation of laminin subunits in parietal endoderm like cells. Biochem. J. 229, 259-264.

Nieder, G.L. (1990) Protein secretion by the mouse trophoblast during attachment and outgrowth in vitro. Biol. Reprod. 43, 251-259.

Richoux, V., Darribere, T., Boucaut, J.C., Flechon, J.E. \& Thiery, J.P. (1989) Distribution of fibronectins and laminin in the early pig embryo. Anat. Rec. 223, 72-81.

Rizzino, A. \& Sherman, M.I. (1979) Development and differentiation of mouse blastocysts in serum-free medium. Expl Cell Res. 121, 221-233.

Semoff, S., Hogan, B.L.M. \& Hopkins, C.R. (1982) Localization of fibronectin, laminin-entactin, and entactin in Reichert's membrane by immunoelectron microscopy. The EMBO Journal 1, 1171-1175.

Smith, K.K. \& Strickland, S. (1981) Structural components and characteristics of Reichert's membrane, an extra-embryonic basement membrane. J. biol. Chem. 256, $4654-4661$.

Solter, D. \& Knowles, B.B. (1975) Immunosurgery of mouse blastocyst. Proc. natn. Acad. Sci. USA 72, 5099-5102.

Strickland, S. (1981) Mouse teratocarcinoma cells: prospects for the study of embryogenesis and neoplasia. Cell 24, 277-278.

Sutherland, A.E., Calarco, P.G. \& Damsky, C.H. (1988) Expression and function of cell surface extracellular matrix receptors in mouse blastocyst attachment and outgrowth. J. Cell Biol. 106, 1331-1348.

Timpl, R., Rhode, H., Robey, P.G., Rennard, S.I., Foidart, J-M. \& Martin, G.R. (1979) Laminin-a glycoprotein from basement membranes. $J$, biol. Chem. 254, 9933-9937.

Turksen, K., Aubin, J.E., Sodek, J. \& Kalnins, V.I. (1984) Changes in the distribution of laminin, fibronectin, type IV collagen and heparan sulfate proteoglycan during colony formation by chick retinal pigment epithelial cells in vitro. Collagen Rel. Res. 4, 413-426.

Wartiovaara, J., Leivo, I. \& Vaheri, A. (1979) Expression of the cell surface-associated glycoprotein, fibronectin in the early mouse embryo. Devl Biol. 69, 247-257.

Wu, T-C., Wan, Y-J., Chung, A.E. \& Damjanov, I. (1983) Immunohistochemical localization of entactin and 
laminin in mouse embryos and fetuses. Devl Biol. 100, 496-505.

Yohkaichtya, T., Hoshini, H. \& Yajima, A. (1988) Fibronectin localization in the mouse embryo from the blastocyst stage to the egg cylinder stage in vitro. Tohoku J. exp. Med. 154, 261-269.
Zetter, B.R. \& Martin, G.R. (1978) Expression of a high molecular weight cell surface glycoprotein (LETS protein) by preimplantation mouse embryos and teratocarcinoma cells. Proc. natn. Acad. Sci, USA. 75, $2324-2328$.

Received 3 May 1990 